\title{
ОТНОСИТЕЛЬНЫЕ ОТКЛИКИ И ИНДЕКСЫ УДЕРЖИВАНИЯ ДЛЯ АНАЛИЗА АЛКИЛРЕЗОРЦИНОВ МЕТОДОМ ГАЗОВОИ ХРОМАТОГРАФИИ
}

Для анализа сложных смесей алкилрезорцинов успешно применяется газо-жидкостная хроматография $\left[{ }^{1-4}\right]$, причем на количественную сторону анализа внимание обрашено лишь в немногих работах [5,6]. Это обусловлено отсутствием эталонных веществ, сложностью их синтеза и очистки. После проведения цикла работ по синтезу индивидуальных алкилрезорцинов нами определены для них относительные отклики катарометра и пламенно-ионизационного детектора (ПИД), а также индексы удерживания.

Относительный мольный отклик $(T)$, определяемый соотношением

$$
\frac{T_{i}}{T_{c}}=\frac{S_{i} M_{i} w_{c}}{S_{c} M_{c} w_{i}}
$$

зависит линейно от молекулярного веса $(M)$ и в алкилароматических соединениях от числа углеродных атомов $(n)$ в боковой цепи $\left[{ }^{7}, 8\right]$.

$$
\begin{aligned}
& T=a+b M, \\
& T=a+b n,
\end{aligned}
$$

где $S$ - площадь пика на хроматограмме,

w - весовая доля компонента' в смеси,

$a, b-$ константы,

$i, c$ - исследуемое и стандартное соединения.

Для 16 моноалкилрезорцинов были определены мольные отклики (табл. 1), на основе которых определялись коэффициенты регрессии $a$ и $b$ (табл. 2). Относительные весовые отклики для всех моноалкилрезорцинов, содержащих в боковой цепи 1-10 атомов углерода (табл. 3), были рассчитаны на основе выведенных уравнений.

Отклики катарометра существенно зависят от молекулярного веса алкилрезорцинов, причем эта зависимость сильнее по сравнению с таковой в случае алкилбензолов. Оба детектора имеют относительно 2-алкилрезорцинов более высокие отклики по сравнению с откликами для 4- и 5-изомеров. Экспериментально определенные значения мольных откликов ПИД удовлетворительно согласуются со значениями откликов, рассчитанными на основе пропорциональной зависимости от числа углеродных атомов в молекуле 4- и 5-алкилрезорцина. Весовые отклики последних постоянны в пределах ошибки опыта, однако для 2-алкилрезорцинов следует применить общий поправочный коэффициент 0,74 . 
Результаты измерений мольных откликов $\left( \pm 2 S_{\bar{x}}\right)$ алкилрезорцинов в катарометре и Пид (бензол принят за 100)

\begin{tabular}{|c|c|c|c|c|c|}
\hline$R$ & Катарометр & пид & $R$ & Катарометр & Пид \\
\hline $\begin{array}{l}\quad \mathrm{H} \\
2-\mathrm{CH}_{3} \\
2-\mathrm{C}_{3} \mathrm{H}_{7} \\
2-\mathrm{C}_{4} \mathrm{H}_{9} \\
2-\mathrm{C}_{6} \mathrm{H}_{13} \\
4-\mathrm{CH}_{3} \\
4-\mathrm{C}_{2} \mathrm{H}_{5} \\
4-\mathrm{C}_{3} \mathrm{H}_{7} \\
4-\mathrm{C}_{4} \mathrm{H}_{9}\end{array}$ & $\begin{array}{c}115^{*} \\
192 \pm 8 \\
229 \pm 10 \\
264 \pm 12 \\
322 \pm 12 \\
131 \pm 3 \\
153 \pm 5 \\
168 \pm 6 \\
189 \pm 6\end{array}$ & $\begin{array}{r}45 \pm 8 \\
83 \pm 6 \\
114 \pm 10 \\
117 \pm 7 \\
128 \pm 10 \\
73 \pm 11 \\
86 \pm 12 \\
75 \pm 7 \\
70 \pm 4\end{array}$ & \begin{tabular}{l} 
4- $\mathrm{C}_{5} \mathrm{H}_{11}$ \\
$4-\mathrm{C}_{6} \mathrm{H}_{13}$ \\
$4-\mathrm{C}_{7} \mathrm{H}_{15}$ \\
4- $\mathrm{C}_{9} \mathrm{H}_{19}$ \\
4- $\mathrm{C}_{10} \mathrm{H}_{21}$ \\
$5-\mathrm{CH}_{3}$ \\
$5-\mathrm{C}_{7} \mathrm{H}_{15}$ \\
$5-\mathrm{C}_{10} \mathrm{H}_{21}$ \\
\multicolumn{1}{c}{-}
\end{tabular} & $\begin{array}{c}242 \pm 10 \\
253 \pm 12 \\
295 \pm 9 \\
348 \pm 11 \\
373 \pm 12 \\
162 \pm 3 \\
294 \pm 11 \\
374 \pm 16 \\
-\end{array}$ & $\begin{array}{r}99 \pm 13 \\
90 \pm 4 \\
110^{*} \\
100 \pm 6 \\
90 \pm 12 \\
61 \pm 3 \\
106 \pm 3 \\
116 \pm 7 \\
-\end{array}$ \\
\hline
\end{tabular}

Таблица 2

Значения постоянных уравнений (2) и (3) для откликов алкилрезорцинов в катарометре и Пид

\begin{tabular}{|c|c|c|c|c|}
\hline \multirow{2}{*}{ Постоянное } & \multicolumn{2}{|c|}{ Уравнение (2) } & \multicolumn{2}{|c|}{ Уравнение (3) } \\
\hline & Катарометр & пид & Катарометр & Пид \\
\hline
\end{tabular}

\begin{tabular}{ccccc}
\multicolumn{5}{c}{ 2-Алкилрезорцин } \\
$a$ & -113 & 9,73 & 135 & 83,2 \\
$b$ & 2,26 & 0,665 & 31,6 & 9,33 \\
$r$ & 0,935 & 0,842 & 0,935 & 0,842 \\
$S$ & 27 & 11 & 27 & 11 \\
\multicolumn{5}{c}{-Алкилезорцины } \\
$a$ & $4-, 5$-Али & \\
$b$ & $-82,3(17,9)^{*}$ & $4,88(-15,7)^{* *}$ & 118 & 60,5 \\
$r$ & $1,82(1,06)^{*}$ & $0,506(0,604)^{* *}$ & 25,5 & 7,08 \\
$S$ & 0,909 & 0,812 & 0,909 & 0,812 \\
& 28 & 12 & 28 & 12
\end{tabular}

* Данные для моноалкилбензолов [7].

** Рассчитаны при предложении, что значения $T_{i}$ пропорциональны числу атомов углерода в молекуле $\left[{ }^{8}\right]$.

На основе откликов ПИд были рассчитаны так наз. числа эффективных углеродов $N_{c}\left[{ }^{9}\right]$

$$
N_{c}=0,07 T_{\mathrm{r}} \cdot M_{i}
$$

где $T_{\mathrm{r}}$ - весовой отклик относительно $\boldsymbol{H}$-гептана.

С удлинением алкильной цепи значения $N_{c}$ увеличивались от 4,18 $(5,57)$ для метилрезорцинов до $7,87(10,6)$ для децилрезорцинов (в скобках указаны значения для 2-алкилрезорцинов). Низкие значения $N_{c}$ обусловлены, по всей вероятности, с одной стороны, особенностями детектирования алкилрезорцинов, а, с другой, тем обстоятельством, что при хроматографировании высококипящих полярных соединений не вся проба доходит до детектора (например от нафторезорцина вообще не удается получить сигнала). По этой же причине при помощи применяемой аппаратуры не удалось хроматографировать в виде фенола 5-н-гептадецилрезорцин. 
Таблица 3

Значения весовых откликов алкилрезорцинов в катарометре и ПиД (резорцин принят за 100)

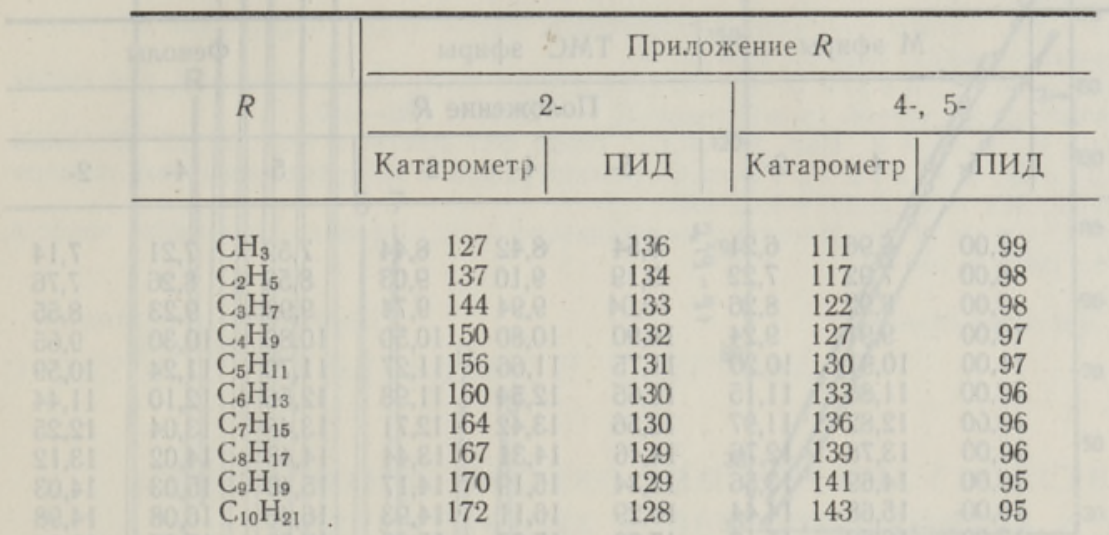

Приведенные выше отклики могут быть использованы также с неко. торым приближением для эфиров фенолов.

Пренебрежение различиями в откликах при анализе смесей алкилрезорцинов ведет к значительным ошибкам, особенно при использовании катарометра.

Индексы удерживания выражены в системе углеродных чисел $\left[{ }^{10}\right]$

$$
C_{X}=C_{A}+\left(\frac{T_{R X}-T_{R A}}{T_{R B}-T_{R A}}\right)\left(C_{B}-C_{A}\right),
$$

где $C$ - углеродное число,

$X$ - определяемое вещество,

$A$ и $B$ - диметиловые эфиры двух 5-алкилрезорцинов, различаюциеся на один углеродный атом,

$T_{R}$ - температура удерживания.

Каждому члену гомологического ряда метиловых эфиров 5-н-алкилрезорцинов приписывается углеродное число, равное числу углеродных атомов в соответствующем феноле. Введение такой системы диктуется доступностью гомологического ряда 5 -алкилрезорцинов $(n \leqslant 17)$ в виде сланцевых двухатомных фенолов, а также удобством выражения результатов определения примесей в последних.

Соблюдается порядок выхода изомеров из колонки $2-<4-<5$ - независимо от того, разделяются алкилрезорцины в виде фенолов или их эфиров (табл. 4). Әто свидетельствует о важной роли кислородного атома при взаимодействии с неподвижной фазой. В случае более коротких цепей все соединения выходят в порядке увеличения молекулярного веса. Начиная с определенной длины цепи 2-изомер выходит раньше, чем 5-изомер, содержащий на один углеродный атом меньше. В этой области перехода (для эфиров при $n \approx 6-8$, для фенолов 3 -4) происходит недостаточное разделение по числу углеродных атомов.

Разделение 2- и 4-изомеров наилучшее в виде метиловых эфиров, a 4- и 5 -изомеров при $n<10-$ в виде фенолов. При $n>10$ последние разделяются лучше также в виде метиловых эфиров. Во всех случаях разделение в внде производных улучшается с увеличением молекулярного веса, а в виде фенолов - ухудшается.

Приведенные значения углеродных чисел были определены в условиях, подходящих для разделения смесей при $n=1 \div 17$. В случае более 
Таб̆лица 4

Значения углеродных чисел алкилрезорцинов и их метиловых (М) и триметилсилиловых (ТМС) эфиров

\begin{tabular}{|c|c|c|c|c|c|c|c|c|c|}
\hline \multirow{3}{*}{$R$} & \multicolumn{3}{|c|}{ M эфиры } & \multicolumn{3}{|c|}{ TMC эфиры } & \multicolumn{3}{|c|}{ Фенолы } \\
\hline & \multicolumn{9}{|c|}{ Положение $R$} \\
\hline & 5. & 4. & $2-$ & $5-$ & $4-$ & $2-$ & $5-$ & $4-$ & 2 \\
\hline $\mathrm{CH}_{3}-$ & 7,00 & 6,96 & 6,21 & 8,54 & 8,42 & 8,44 & 7,52 & 7,21 & 7,14 \\
\hline $\mathrm{C}_{2} \mathrm{H}_{5}-$ & 8,00 & 7,92 & 7,22 & 9,19 & 9,10 & 9,03 & 8,52 & 8,26 & 7,76 \\
\hline $\mathrm{C}_{3} \mathrm{H}_{7}-$ & 9,00 & 8,92 & 8,26 & 10,04 & 9,94 & 9,74 & 9,92 & 9,23 & 8,55 \\
\hline $\mathrm{C}_{4} \mathrm{H}_{9}-$ & 10,00 & 9,91 & 9,24 & 10,90 & 10,80 & 10,50 & 10,80 & 10,30 & 9,65 \\
\hline $\mathrm{C}_{5} \mathrm{H}_{11}-$ & 11,00 & 10,91 & 10,20 & 11,75 & 11,66 & 11,27 & 11,70 & 11,24 & 10,59 \\
\hline $\mathrm{C}_{6} \mathrm{H}_{13}-$ & 12,00 & 11,88 & 11,15 & 12,65 & 12,54 & 11,98 & 12,56 & 12,10 & 11,44 \\
\hline $\mathrm{C}_{7} \mathrm{H}_{15}-$ & 13,60 & 12,82 & 11,97 & 13,56 & 13,42 & 12,71 & 13,48 & 13,04 & 12,25 \\
\hline $\mathrm{C}_{8} \mathrm{H}_{17}-$ & 14,00 & 13,78 & 12,76 & 14,46 & 14,31 & 13,44 & 14,43 & 14,02 & 13,12 \\
\hline $\mathrm{C}_{9} \mathrm{H}_{19}-$ & 15,00 & 14,69 & 13,56 & 15,34 & 15,19 & 14,17 & 15,40 & 15,03 & 14,03 \\
\hline $\mathrm{C}_{10} \mathrm{H}_{21}-$ & 16,00 & 15,68 & 14,44 & 16.29 & 16,11 & 14,93 & 16,43 & 16,08 & 14,98 \\
\hline $\mathrm{C}_{11} \mathrm{H}_{23}-$ & 17,00 & 16,58 & 15,18 & 17,22 & 17,03 & 15,65 & 17,52 & 17,22 & 15,94 \\
\hline $\mathrm{C}_{12} \mathrm{H}_{25}-$ & 18,00 & 17,47 & 15,98 & 18,13 & 17,93 & 16,38 & 18,61 & 18,36 & 16,99 \\
\hline $\mathrm{U}_{13} \mathrm{H}_{27}-$ & 19,00 & 18,50 & 16,84 & 19,01 & 18,81 & 17,14 & 19,70 & 19,50 & 18,05 \\
\hline $\mathrm{C}_{14} \mathrm{H}_{29}-$ & 20,00 & 19,43 & 17,70 & 19,93 & 19,73 & 17,93 & - & - & - \\
\hline $\mathrm{C}_{15} \mathrm{H}_{31}-$ & $21, \mathrm{CO}$ & 20,38 & 18,54 & 20,88 & 20,62 & 18,70 & - & - & - \\
\hline $\mathrm{C}_{16} \mathrm{H}_{33}-$ & 22,00 & 21,33 & 19,40 & 21,82 & 21,58 & $19,5 \mathrm{i}$ & - & - & - \\
\hline $\mathrm{C}_{17} \mathrm{H}_{35}-$ & 23,00 & 22,29 & 20.26 & 22,77 & 22,43 & 20,27 & - & - & - \\
\hline
\end{tabular}

узких фракций для конкретной смеси можно выбрать более оптимальные условия. Однако углеродные числа, как и индексы Ковача, относительно мало зависят от температуры, и поэтому приведенные значения могут быть использованы при другой программе или даже для определения порядка выхода алкилрезорцинов при хроматографировании в изотермических условиях.

\section{Экспериментальная часть}

Эталонные вещества с чистотой выше 90\% были синтезированы в основном в нашей лаборатории. При определении значений $T_{R}$ были использованы, кроме перечисленных в табл. 1 соединений, еще эфиры 5-метил-2-нонил-, 5-метил-2-гексадецил- и 5-гептадецилрезорцина, а также сланцевые двухатомные фенолы (и их эфиры) с молекулярным весом 210.

Измерения выполнялись на хроматографе GC-1C фирмы «Шимадзу». Применялась колонка длиной $110 \mathrm{~cm}$ и диаметром 3 мм с $10 \%$ апиезона $L$ на хромосорбе $W$ (рис. 1). Температура детектора и испарителя составляла соответственно 300 и $400-490^{\circ} \mathrm{C}$ (при температуре $300-350^{\circ}$ в испарителе отклики были ниже). Температура колонки программировалась от 130 до $320^{\circ}$ со скоростью 2 или $4^{\circ}$ в минуту (по диску прибора). Фактическая скорость по ртутному термометру составляла соответственно 1,85 (при определении индексов удерживания) и $3,6^{\circ}$ в минуту (при измерении откликов). Скорость гелия в начале программы - 40 мл в минуту, постоянное давление до колонны - 1,2 ати. Скорость водорода для ПИД - 40 мл/мин, давление воздуха 0,8 aтu.

Измерения проводились 5-10 раз. Значения $T$ рассчитывались по уравнению (1). Площади пиков были переведены на начальную скорость гелия согласно [10]. В качестве стандарта в катарометре служил резорцин $\left(T_{c}=115\right.$ относительно бензола), а в ПИД - 4-гептилрезорцин $\left(T_{e}=110\right)$. 


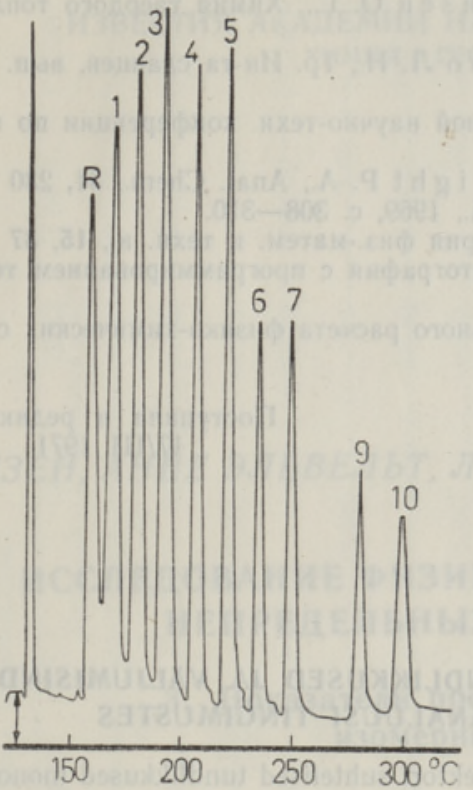

Рнс. 1. Хроматограмма гомологического ряда 4-н-алкилрезорцинов. На пиках указаны значения $n \cdot R-$ резорцин.

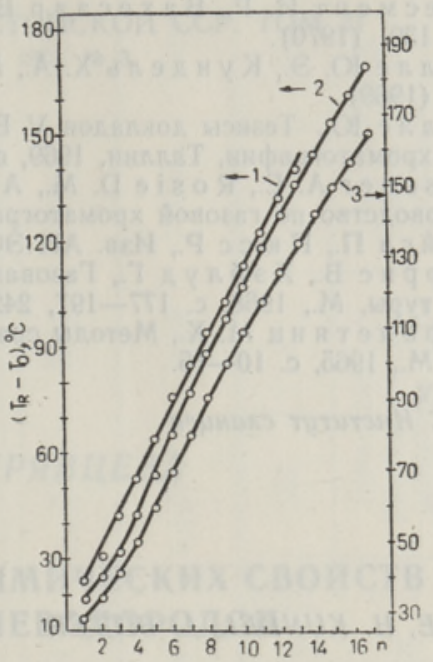

Рис. 2. Зависимость $T_{R}=f(n)$ для 5-алкилрезорцинов в виде фенолов (1), метиловых (2) и триметилсилиловых (3) эфиров.

Регрессионный анализ проводился на электронно-вычислительной машине «Наири-С» методом наименьших квадратов с достоверностью $95 \%$.

Значения $T_{R}$ для отсутствующих членов гомологических рядов определялись либо экстра- и интерполированием (для фенолов), либо методом сравнительного расчета [3,11] (для эфиров). На рис. 2 показаны зависимости $T_{R}=f(n)$ для 5-алкилрезорцинов.

\section{Выводы}

1. Определены относительные мольные огклики моноалкилрезорцинов, содержащих до 16 атомов углерода в молекуле, в катарометре и в пламенно-ионизационном детекторе. Пренебрежение различиями в откликах отдельных соединений ведет к значительным ошибкам, особенно в случае катарометра.

2. Для выражения данных удерживания алкилрезорцинов предложена шкала углеродных чисел, в основу которой взят гомологический ряд метиловых эфиров 5-алкилрезорцинов.

3. Определены углеродные числа для моноалкилрезорцинов, содержащих до 23 атомов углерода в молекуле в виде свободных фенолов, метиловых и триметилсилиловых эфиров.

\section{ЛИТЕРА Т Р А}

1. Лилле Ю. Э., Кундель Х. А., Тр. Ин-та сланцев, вып. 16, 186 (1967).

2. Лилле Ю. Э., Биттер Л. А., К ундель Х. А., Бюл. Горючие сланщы, № 3, 19 (1969).

3. Клесмент И. Р., В ахес а ар В. А., Эй зен О. Г., Изв. АН ЭССР, Хим. Геол., 18, 391 (1969). 
4. Клесмент И. Р., В ахес а а р В. А., Э й зен О. Г., Химия твердого топлива, 5, 139 (1970)

5. Л илле Ю. Э., К унде ль Х. А., М алько Л. Н., Тр. Ин-та сланцев, вып. 18, 119 (1969).

6. Лилле Ю., Тезисы докладов V Всесоюзной научно-техн. конференции по газовой хроматографии, Таллин, 1969 , с. 35 .

7. Messner A. E., Rosie D. M., Argabright P. A., Anal. Chem., 31, 230 (1959).

8. Руководство по газовой хроматографии, М., 1969, с. 308-310.

9. Лу й г а П., Пюс с Р., Изв. АН ЭССР, серия физ.-матем. и техн. н., 15, 37 (1966).

10. Х а р р и с В., Х э бл уд Г., Газовая хроматография с программированием температуры, М., 1968 , с. $177-197,242$.

11. К а р а п е т я н $М$. Х., Методы сравнительного расчета физико-химических свойств, M., 1965 , c. $10-15$.

НИНС Ннститут сланцев

Поступила в редакцию 17/III 1971

O. LILLE, H. KUNDEL, L. BITTER

\section{ALKUOLRESORTSIINIDE SUHTELISED TUNDLIKKUSED JA VÄLJUMISINDEKSID GAASIKROMATOGRAAFILISE ANALUUSI TINGIMUSTES}

Määrati kataromeetri ja leek-ionisatsioonidetektori suhtelised tundlikkused monoalküülresortsiinide suhtes $(M \leqslant 250)$ ja viimaste nn. süsinikuarvud apiezoonikolonni temperatuuri programmeeritud tõusu puhul $(M \leqslant 348)$. Süsinikuarvude määramisel kasutati standardühendina 5 -alküülresortsiinide metüüleetrite homoloogilist rida.

\section{O. LILLE, H. KUNDEL, L. BITTER}

\section{RELATIVE RESPONSES AND RETENTION INDEXES FOR GAS-CHROMATOGRAPHIC ANALYSIS OF ALKYLRESORCINOLS}

Relative responses of katharometer and flame ionization detector for monoalkylresorcinols $(M \leqslant 250)$ and the so-called carbon numbers for the latter $(M \leqslant 348)$ were determined. Homologous methylethers of 5-alkylresorcinols were used as standards to determine the carbon numbers. 